\title{
Atypical neurological manifestations of malaria
}

\author{
Neeraj Singla, Monica Gupta, Ram Singh, Ashwani Kumar
}

Department of Medicine, Government Medical College and Hospital, Chandigarh, India

\section{Correspondence to} Dr Neeraj Singla, neerajsingladr@yahoo.co.in

Accepted 6 August 2014

\section{SUMMARY}

Malaria is known as a great mimic. It can manifest subtly or abruptly, typically or atypically. This aspect of the disease can frequently mislead physicians. We present two patients of malaria with atypical neurological manifestations. The first patient of Plasmodium falciparum malaria presented with fever and altered sensorium; MRI of the brain suggested cerebral venous thrombosis. The second patient of Plasmodium vivax presented with fever, double vision and right eye lateral rectus palsy due to unilateral sixth cranial nerve involvement. Both patients were managed with antimalarials and supportive medical management, and had uneventful recoveries.

\section{BACKGROUND}

Malaria, caused by intraerythrocytic protozoa of the genus Plasmodium, is still one of the leading causes of morbidity and mortality in humans. ${ }^{1} 2$ Humans are infected by one or more of the following species: Plasmodium falciparum, P. vivax, P. ovale, P. malariae and P. knowlesi. Malaria presents classically with febrile paroxysms, sweating and rigours associated with myalgia, headache and abdominal discomfort. There are numerous reports highlighting the atypical manifestations of falciparum as well as vivax malaria. Development of immunity, indiscriminate use of antimalarial drugs and increasing drug resistance have been responsible for malaria presenting with unusual features in endemic areas.

We report two cases of malaria with neurological manifestations, one of $P$. falciparum malaria with cerebral venous thrombosis (CVT) and the other of P.vivax malaria with unilateral lateral rectus palsy.

\section{CASE PRESENTATION}

\section{Case 1}

A 24-year-old married woman was admitted to our medical unit with fever for the past 7 days and altered sensorium for 1 day. The patient had no history of headache, vomiting, seizures or any bleeding manifestation. At the time of admission, her Glasgow Coma Scale (GCS) was 9. Neck rigidity was present. Her pupils were mildly dilated and reacting to light. Vitals were normal and other systemic examination was unremarkable. There was no history of use of oral contraceptives and no significant history contributory to disease.

\section{Case 2}

A 14-year-old girl was admitted with fever for the past 8 days associated with double vision for 2 days and deviation of the right eye inwards. The patient had no history of loss of consciousness, shortness of breath or any bleeding manifestation. On examination, she was conscious. Both her pupils were of normal size and reacted normally to light. The left eye showed subconjunctival haemorrhage and the right eye had lateral rectus palsy. On fundus examination papillo-oedema was present. Vitals were stable. No other focal neurological deficit was seen.

\section{INVESTIGATIONS}

Case 1

Laboratory findings of the first patient showed haemoglobin $(\mathrm{Hb}) 6.1 \mathrm{~g} / \mathrm{dL}$ and white cell count (WCC) $7600 / \mu \mathrm{L}$ (neutrophils 60\%, lymphocytes $37 \%$ and monocytes 3\%). Peripheral blood smear (PBS) showed schizonts of P. falciparum. Platelet count was (PC) $20000 / \mu \mathrm{L}$. Lumbar puncture was done; cerebrospinal fluid (CSF) was acellular, sugar $50 \mathrm{mg} / \mathrm{dL}$, protein $38 \mathrm{mg} / \mathrm{dL}$ and culture sterile. MRI of the brain showed normal signal void of superior sagittal sinus in sagittal imaging, which was highly suggestive of cortical venous sinus thrombosis (figures 1).

\section{Case 2}

Blood counts of the second patient revealed $\mathrm{Hb}$ $11.7 \mathrm{~g} / \mathrm{dL}$, WCC $6700 / \mu \mathrm{L}$ (neutrophils 78\%, lymphocytes $17 \%$ and eosinophils $2 \%$ ) and PC $15000 / \mu \mathrm{L}$. PBS film showed schizonts of P. vivax. Non-contrast CT of the brain was normal. MRI of the brain was planned, but since the patient started improving, her relatives refused any further investigations due to financial constraints.

\section{DIFFERENTIAL DIAGNOSIS}

On the basis of the history and clinical features, differential diagnosis of viral encephalitis, acute pyogenic meningitis, tubercular meningitis (TBM) and pontine infarct were considered as possible diagnoses. Patients with viral encephalitis generally present with a similar history of fever and altered sensorium as in our first patient, but as her CSF was normal and MRI was suggestive of CVT, it was excluded.

Both the cases presented with fever of 1 week duration; however, since the CSF examination was normal, possibilities of TBM and acute pyogenic meningitis could not be further considered. Moreover, both patients started responding well to antimalarials during hospital stay. Although patients with pontine infarct may also present with cranial nerve palsies, both patients showed marked improvement after antimalarial therapy alone, so the diagnosis of pontine infarct was implausible. 

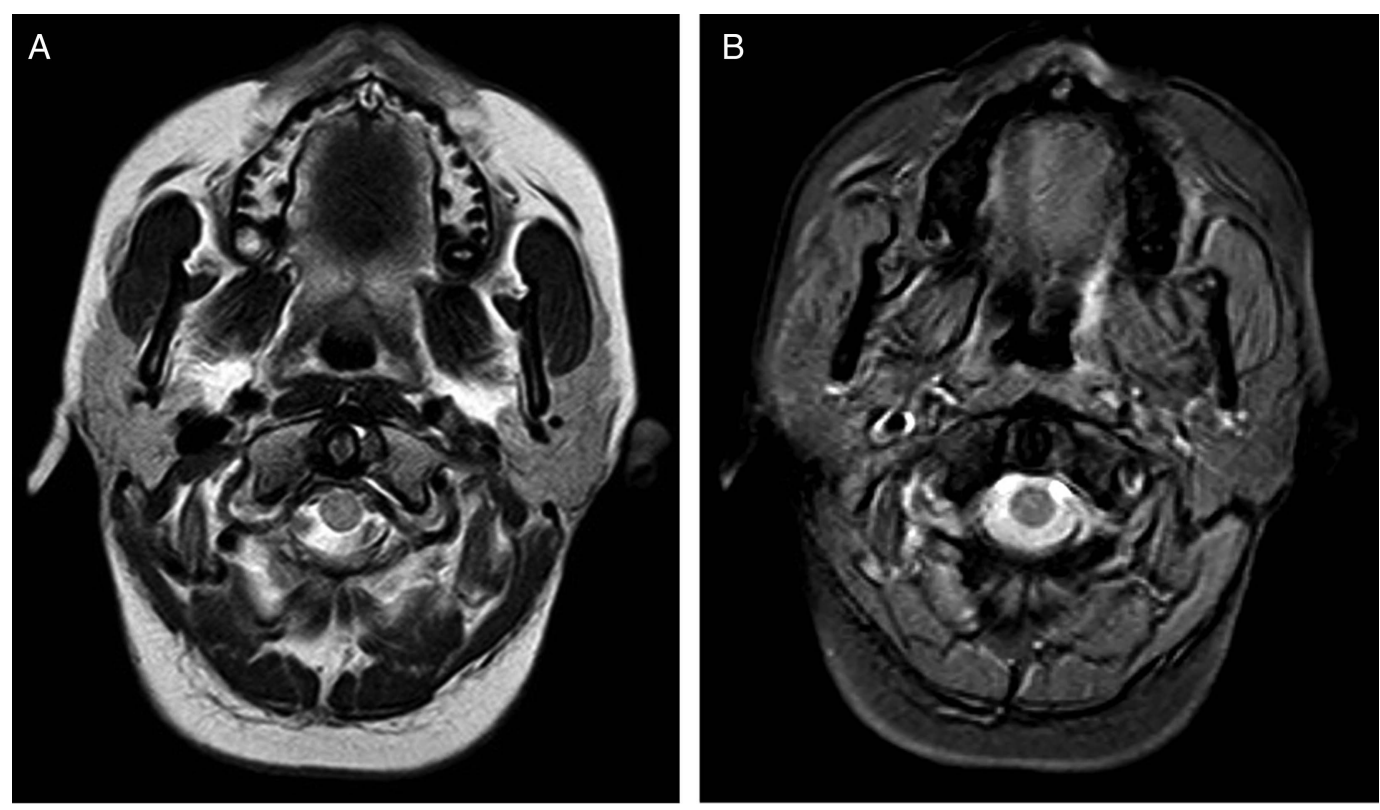

Figure $1 \mathrm{MRI}$ of the brain suggestive of sagittal venous thrombosis.

\section{TREATMENT, OUTCOME AND FOLLOW-UP}

Both patients were treated with parenteral artesunate $120 \mathrm{mg}$ once daily for 7 days. In addition, the patient with CVT was also given low molecular weight heparin subcutaneously for 7 days. She started improving after treatment. Her GCS improved and she was fully conscious after 7 days. At the time of discharge her $\mathrm{Hb}$ was $12 \mathrm{~g} / \mathrm{dL}$, PC $180000 / \mu \mathrm{L}$ and all routine laboratory parameters were within normal range. PBS showed no parasitaemia at 1 week. She was discharged with no neurological sequelae and oral anticoagulants were given for 3 months.

Since the second patient developed excessive vaginal bleeding on the second day of admission, she was also transfused 4 units of random donor platelets. After 7 days of treatment, her PC $232000 / \mu \mathrm{L}$ was seen and on follow-up, diplopia and rectus palsy had improved.

\section{DISCUSSION}

CVT is a distinct cerebrovascular disorder that is reported in various infections but very few cases of CVT associated with malaria are reported. ${ }^{3}{ }^{4}$ Various risk factors for CVT include genetic prothrombic conditions (factor $\mathrm{V}$ Leiden mutation, protein $\mathrm{C}$ and $\mathrm{S}$ deficiency, antithrombin deficiency); acquired prothrombic states (pregnancy, puerperium, homocysteinaemia, antiphospholipid antibodies); inflammatory disease (Behcet syndrome, systemic lupus erythematosus, inflammatory bowel disease); infections (meningitis, systemic infectious disease) and use of oral contraceptives. ${ }^{5}$ Unusual causes of CVT include abdominal tuberculosis, ${ }^{6}$ falciparum malaria, air travel, ${ }^{7}$ etc.

Our first case of malaria presented with CVT. Thrombosis in malaria is believed to be due to hypercoagulability, which can be caused by altered phospholipids in malaria infected cells leading to an increased von Willebrand factor. ${ }^{8}$ Besides this, increased tissue factor released from damaged endothelial cells may also cause hypercoagulability. ${ }^{9}$ Patients with CVT should be treated with low-molecular-weight heparin or intravenous heparin and oral anticoagulants may be given for 3 months, but the optimal duration is unclear. ${ }^{10}$ Since early diagnosis improves outcome, clinicians should be vigilant in considering it in $P$. falciparum malaria.

Severe complications of malaria, either sequestration (cerebral malaria) or non-sequestration related (anaemia, thrombocytopaenia), have been traditionally attributed to falciparum malaria or mixed infections. In recent times, many unusual complications with $P$. vivax such as cerebellar dysfunction, ${ }^{11}$ meningoencephalitis, ${ }^{12}$ acute disseminated encephalomyelitis, ${ }^{13}$ CVT and bilateral sixth nerve palsy, ${ }^{14}{ }^{15}$ have been reported, but unilateral sixth nerve palsy in $P$. vivax malaria has not been reported to date. Various causes of sixth nerve palsy are vasculopathic (diabetes mellitus, hypertension and atherosclerosis), trauma, idiopathic, increased intracranial pressure, cavernous sinus mass (meningioma, metastasis), sarcoidosis, vasculitis, stroke and multiple sclerosis. Sixth nerve palsy in our second patient was probably due to raised intracranial tension, which may have been a false localising sign. Unfortunately, the cause for unilateral palsy could not be ascertained in this patient. Although sequestration is usually not considered in pathophysiology of $P$. vivax, with the above mentioned complications this assumption must now be challenged. Further research is required to ascertain the aetiology of these manifestations.

\section{Learning points}

- Not only Plasmodium falciparum, but $P$. vivax malaria can also present with atypical neurological manifestations.

- Hypercoagulability due to an increased von Willebrand factor may be responsible for cortical venous thrombosis in severe falciparum malaria.

- Unilateral lateral rectus palsy can also be a manifestation of P. vivax malaria.

- To decrease the morbidity and mortality associated with malaria, physicians must be aware of unusual manifestations. 
Contributors NS and MG were involved in final diagnoses, management, writing the manuscript and review of the literature. RS, head of the department undertook the final review of the manuscript and literature in detail. AK initially diagnosed the patients and collected the data for preparing the manuscript.

Competing interests None.

Patient consent Obtained.

Provenance and peer review Not commissioned; externally peer reviewed.

\section{REFERENCES}

1 Greenwood B, Mutabingwa T. Malaria in 2002. Nature 2002:415:670-2.

2 Krause PJ. Malaria (Plasmodium). In: Behrman RE, Kliegman RM, Jenson HB, eds. Nelson textbook of pediatrics. 18th edn. Philadelphia, PA: WB Saunders, 2007:1477-85.

3 Luvira V, Chamnanchanunt S, Thanachartwet V, et al. Cerebral venous thrombosis in falciparum malaria. South East Asian J Trop Med Public Health 2009;40:893-7.

4 Krishnan A, Karnad DR, Limaye U, et al. Cerebral venous and dural sinus thrombosis in severe falciparum malaria. J Infect 2004;48:86-90.

5 Stam J. Thrombosis of the cerebral veins and sinuses. N Engl J Med 2005;352:1791-8.

6 Fiorot Júnior JA, Felício AC, Fukujima MM, et al. Tuberculosis: an uncommon cause of cerebral venous thrombosis? Arq Neuropsiquiatr 2005;63:852-4.
7 Grotta JC. Cerebral venous thrombosis—a new diagnosis in travel medicine. J Travel Med 1996;3:137.

8 Ghosh K, Shetty S. Blood coagulation in falciparum malaria-a review. Parasitol Res 2008; 102:571-6.

9 Francischetti IM, Seydel KB, Monteiro RQ, et al. Plasmodium falciparum-infected erythrocytes induce tissue factor expression in endothelial cells and support the assembly of multi-molecular coagulation complexes. I Thromb Haemost 2007:5:155-65.

10 Einhäupl K, Stam J, Bousser MG, et al. EFNS guideline on the treatment of cerebral venous and sinus thrombosis in adult patients. Eur I Neurol 2010;17: 1229-35

11 Taksande B, Jajoo U, Jajoo M. Cerebellar malaria: a rare manifestation of Plasmodium vivax. Internet J Neurol 2006;7:1.

12 Sarkar S, Bhattacharya P. Cerebral malaria caused by Plasmodium vivax in adult subjects. Indian I Crit Care Med 2008;12:204-5.

13 Goyal JP, Shah VB, Parmar S. Acute disseminated encephalomyelitis after treatment of Plasmodium vivax malaria. J Vector Borne Dis 2012;49:119-21.

14 Vinod KV, Talari K, Gopalakrishnan M, et al. Unusual presentations of vivax malaria: a report of two cases. J Vector Borne Dis 2012:49:49-51.

15 Lala K, Lala D, Mukherji A, et al. Cerebral venous thrombosis in a case of P. vivax malaria. J Trop Dis 2013;1:105.

Copyright 2014 BMJ Publishing Group. All rights reserved. For permission to reuse any of this content visit

http://group.bmj.com/group/rights-licensing/permissions.

BMJ Case Report Fellows may re-use this article for personal use and teaching without any further permission.

Become a Fellow of BMJ Case Reports today and you can:

- Submit as many cases as you like

- Enjoy fast sympathetic peer review and rapid publication of accepted articles

- Access all the published articles

- Re-use any of the published material for personal use and teaching without further permission

For information on Institutional Fellowships contact consortiasales@bmjgroup.com

Visit casereports.bmj.com for more articles like this and to become a Fellow 